\title{
feminist sublimations, queer disidentifications: losing touch of maternal sexuality
}

\author{
Susan Driver
}

\begin{abstract}
Dans son essai, Susan Driver écrit "mon désir de réorienter les lectures psychanalytiques féministes et 'queer' du maternel loin des bipolarités normatives vers une plus grande attention aux personnifications de la subjectivité maternelle nuancées (con)textuellement est déterminé par ce que je considère être quelques-uns des aspects les plus curieux émergeant de ces projets théoriques qui tendent au-delà des idéologies de reproduction maternelle." Troublée par "l'omniprésence des constructions binaires qui divisent les sexualités subversives des normes éthiques de la maternité," elle démontre les échecs des critiques psychanalytiques féministes et 'queer' de théoriser efficacement les "imbrications de l'amour et du désir sexuel maternel." En se tournant vers l'oeuvre de Teresa de Lauretis, elle espère rediriger la conversation entre les critiques féministes et 'queer'.
\end{abstract}

Imbrications of mother love and lust continue to provoke intimate anxieties and theoretical defences through which maternal identifications become split off from non-reproductive sexual desires and pleasures. While dichotomous frameworks of sexuality and motherhood are not so surprising when enacted by patriarchal thinkers who flinch at femininematernal embodiments (as Luce Irigaray has shown through her deft readings), they are an unexpected feature of feminist and queer psychoanalytic thought. At a moment in history when heterogeneous sexualities are being critically and creatively explored in highly inventive ways, pervasive subjective and cultural ambivalences surround maternal subjects who partake of erotically complex transferences/transformations. Ambivalence can be traced in the ways feminist and queer psychoanalytic theories separate problems of motherhood and sexuality into disparate areas of specialization, with feminist thinkers affirming ethical and relational values of mothering and queer thinkers focusing as far away from maternal bonds as possible in order to theorize sites of gender parody and sexual transgression. Between a relational presence of motherhood harbored within feminist developmental narratives and an absence of maternal desire in queer counter-narratives, disruptive maternal desires get left out of many contemporary theoretical purviews. 
What remains uncertain is whether a more productive understanding of maternal sexuality might emerge at intersections of discordant social and theoretical movements. Perhaps tensions produced out of maternal ambivalence might enable a dialogue between feminist and queer psychoanalytic perspectives capable of calling into question exclusionary presumptions that have marked their differences? Maybe by sharpening the contradictions between feminist and queer positions on motherhood, a more open and reflexive relation between an ethics of care and sexual indeterminacy can emerge? Might cross-overs between feminism and queer interests promote a respect for maternal specificities unhinged from rigid logics of sexual difference and heteronormativity? Does this offer a chance to relieve motherhood of the burden of sustaining rigid sex/gender systems? Will such rethinkings provide queerly positioned daughters alternative ways of imagining their maternal identifications? Does this call for an extensive questioning of the class and racial hierarchies underpinning maternal-sexual ideologies? To begin to answer such questions, I will sketch some limitations within contemporary psychoanalytic theories and indicate theoretical points of departure for thinking otherwise.

\section{heteronormalized ethics of maternal love}

Formulating a new discourse about maternity presumes that, without giving up the cultural instruments that have allowed for this criticism, we can liberate ourselves of cultural encrustations. It presumes that the coordinates that organize maternity, the images that sustain it, the words that conceal it, can all be disassembled. In the emptiness thus obtained, new images and unforeseen configurations of meaning, different ways of relating to ourselves and to others, may emerge. Above all, we must manage to resist the urge to fill the void with new, definitive inscriptions and limit ourselves to practicing "a long lasting research." (Finzi 140)

Some of the most productive aspects of feminist psychoanalytic thinking attempt to recast maternal subjectivity as an ethical and culturally viable relational process. Validating a mother as a speaking and desiring subject who is given as much theoretical attention as a child's conscious and unconscious maternal fantasies, feminist psychoanalytic theories are increasingly responsive to maternal perspectives. Focusing on mothers as historically situated speaking subjects who are dynamically configured through fantasmatic as well as socio-cultural relations, feminist analyses 
can be understood as challenging reductive models of the Mother as an intrapsychic or sociological object. While such reorientations have created space to counterpoise various levels of maternal desire and identification, I want to indicate blind spots through which sexuality continues to be treated as either unimportant to questions of maternal identity and practice or is subsumed within heteronormative frameworks centred upon sexual difference. This leads to uncritical versions of gender complimentarity, and it also disavows the racialized and class stratifications that have shaped psycho-social oppositions between sexually deviant and sexually normative ideals of mothering.

In The Bonds of Love, Jessica Benjamin theorizes mothering as an intersubjective and communicative activity capable of resisting dominant discourses of maternal passivity. By tracing reciprocal exchanges between mother and child, mothering becomes a privileged site of ethical engagements with others as well as an origin of the breakdown of reciprocity into gendered poles of domination and subordination. Concerned with complex psychic struggles for recognition between mother and child situated within broader discursive and material contexts of domination, Benjamin expands the scope of object relations theory beyond privatized dyadic paradigms toward a problematization of psycho-sexuality in terms of the gendered dimensions of socio-historical power relations. Benjamin's dialectical strategies of critique examine the ways maternal subjects actively negotiate public powers which deny maternal recognition as well as specifying localized intersubjective patterns which counter institutional denials of maternal differences. In Like Subjects, Love Objects, Benjamin undertakes multi-layered readings of maternal figures, writing that "the images, narratives, and harbingers of the maternal transference may be different" (157) allowing for culturally complex and changing maternal desires and identifications as conducive to primary structurations mutual recognition.

But while Benjamin offers useful reconceptualizations of mothering as an intersubjective practice, she tends to separate receptive, empathic and nurturing dimensions of mothering from those aspects of sexual desire, fantasy and pleasure which destabilize conventional reproductive sexualities. Many aspects of sexual fantasy and bodily experience are split off from relational aspects of mutual recognition in Benjamin's writings. The erotic dimensions of a child's intersubjectivity become structured according to gender alignments which leave very little room to consider multiple and contradictory sexualities. Even more problematic is Benjamin's generalizations about a lack of maternal sexual desire not only at the level 
of symbolic ideals but also as a pervasive experiential reality effecting mothers and daughters. Benjamin asserts in no uncertain terms that "the mother is not articulated as a sexual subject, one who actively desires something for herself-quite the contrary. The mother is a profoundly desexualized figure" (Bonds 88). Although Benjamin conceptualizes the importance of maternal desire, her ideas are circumscribed by the ethical prerequisites of recognition based on sexual difference. Excluding "unruly," aggressive, and unstable instances of maternal sexuality which exceed dialectical logics underlying her theoretical truth claims, Benjamin reveals her own desire for continuity and control in relation to maternal subjectivity. It seems that even Benjamin's innovative uses of object relations theory relies on regulative assumptions about sexuality and motherhood: valorizing a mother's empathic presence and plenitude in order to compensate for her erotic absence and lack. Not only does this sublate instances of pleasure and desire as middle terms of a dialectical narrative of recognition but it also promotes middle class maternal paradigms of individuation, self-control and rational coherence.

In a different vein, Lacanian feminists have challenged reified inscriptions of the imaginary and symbolic Mother for heterogeneous maternal signifers of desire. Against the erasure of maternal subjectivity in Freudian and Lacanian theory according to which the Mother is a projection of the child's narcissistic desire for phallic fulfillment, Julia Kristeva's early writings have gone a long way toward understanding maternal subjectivity in terms of intricate foldings of materiality and language. Inscribing the maternal body as an interactive semiotic process, Kristeva shifts away from abstract linguistic laws which legitimize paternal authority, toward complex readings of sounds, images, affects and meanings refracted through the social embodiments of maternal subjects. Kristeva disturbs unified and rational ideologies of mothering without denying the psychic, social and ethical values of maternal subjects framed in terms of intertextuality. Theorizing motherhood according to dialogical modes of address which engage bodily acts of desire, Kristeva overcomes the binary tendencies of dialectical knowledges. This enables Kristeva to portray the maternal as a productive locus of psychic alterity and negativity, while also proclaiming the maternal as a "pivot of sociality." The mediational status of motherhood between psychic interiority and historical contextuality ensures a productive ambivalence that resists theoretical closure.

But although Kristeva respects mobile and connective qualities of preoedipal mother-child interactions, when it comes to socially meaningful 
sexual relations, Kristeva appeals to a teleology of heterosexuality as a means to stabilize desire. Aesthetic sublimations of maternal alterity (enacted by male artists) become the privileged locus of semiotic disruption of symbolic normativity while maternal subjects are positioned within conventional reproductive structures. Kristeva ultimately tames the heterogeneity of maternal sexuality by privileging a heterosexual family romance as a necessary guarantee of socio-symbolic intelligibility. In Tales of Love, Kristeva deploys metaphors which imply (hetero)sexual difference as the basis for desire and identification, in relation to which homoerotism is pathologized as psychotic traces of unresolved attachment to the mother's body. She writes that:

lesbian loves comprise the delightful arena of a neutralized, filtered libido, devoid of the erotic cutting edge of masculine sexuality. Light touches, caresses, barely distinct images fading one into the other growing dimmer veiled without bright flashes into the mellowness of a dissolution, a liquefaction, a merger...It evokes the loving dialogue of the pregnant mother with the fruit, barely distinct from her, that she shelters in her womb. (81)

Kristeva's poetic image of a fusional maternal-lesbian eroticism forecloses any possibility for symbolic difference and desire as constitutive of relations between women. Although Kristeva allows maternal embodiment to become a dynamic signifying force in sharp contrast to the inertia of Lacanian models, she oedipalizes sexuality insisting upon a mode of individuation that necessitates separation from the mother whose own desire is paternally mediated. Giving more consideration to bodily desires than Benjamin's object relational perspective, Kristeva goes no further in disrupting its heteronormative implications. While Kristeva exalts the dissident potentials of the maternal body as exceeding moral codes and rational logics, she contains maternal sexuality within nuclear family scenarios through which she manages her own ambivalent relation to nonheterosexual desires. It becomes clear that mothers who defy dominant socio-symbolic norms are seen as reactive and ineffectual:

This has its extreme: in the refusal of the paternal function by lesbian and single mothers can be seen one of the most violent forms taken above, as well as one of the most fervent divinisations of maternal power-all of which cannot help but trouble an entire legal and moral order without, however, proposing an alternative to it. (“Women's" 210) 


\section{queer disarticulations of motherhood and desire}

Maternal bodies/selves are framed by feminist psychoanalytic theorists in ways that normalize sexual desires for the sake of social and ethical continuity within prescriptive familial narratives. Attempting to problematize normative readings of gender and sexuality, queer theorists such as Judith Butler and Diana Fuss offer readings which shift emphasis toward the semiotic and psychic permeability of man/woman, maternal/paternal and hetero/homosexual boundaries. Interrogating universal models of gender with a performative unleashing of mobile forces of desire, queer theorists offer strategies for thinking unpredictably about desiring subjectivities. But while they offer a range of possibilities for displacing binary identities, the maternal becomes associated with the intransigent forms of gender normativity. Biddy Martin argues that queer theory "conceives gender in negative terms of fixity, miring or subjection to the female body, with the consequence that escape from gender, usually in the form of disembodiment and always in the form of gender crossing, becomes the goal." Martin claims that the conventionality of gender is often seen as coincident with "the feminine" as "a capitulation, a swamp, something maternal, ensnared and ensnaring," (105) in contrast to which the defiant excesses of sexuality represent non-conformity and risk. Martin's reference to "something maternal" points to the ways maternal subjectivity continues to be thought in terms of corporeal and symbolic inertia against which queer sexual mobility and defiance are celebrated. Queer theory's maternal notions end up reinforcing oppositions between desiring movements of sexual outlaws and static embodiments of women's reproductive sexuality.

Judith Butler has elaborated psychoanalytic insights throughout her writings to account for gender as a discursively mediated fantasy which facilitates bodily materializations of desire. Her attempts to theorize corporeality in terms of a performative inscription of "words, acts, gestures and desire" on the surface of the body, interweave psychic effects through and against regulative discourses. Butler's Foucauldian bent encourages transitive modes of sexuality and the categories of sex and gender they produce. Combining Foucault's historical approach with a psychoanalytic account of the "psychic which exceeds the domain of the conscious subject," ("Imitation" 24) Butler is interested in hypothesizing psychical dynamics sustaining the cultural abjection of homosexual desire. Analyzing the exclusivity of normative heterosexuality through a model of melancholia and incorporation in which the cultural failure to mourn socially prescribed losses of same-sex love result in rigid gender identities, Butler sketches the psychic effects of socio-historical prohibitions. She also 
makes use of Freudian and Lacanian terms to elaborate a theory of gender identification and desire that uproots patterns of psychic investment and loss from a model based on precultural incestuous desires for the parental figure of the opposite sex. In Butler's reading, a fantasy of incest is itself produced through the regulative powers of compulsory heterosexuality, a fantasy which like any other is culturally contingent and open to resignification. As such, sexuality and gender are not straightforward replications of a paternal Law or a patriarchal structure of kinship, but are provisional repetitions of heterosexist constructs open to "denaturalization and critical mobilization." She writes:

the unconscious is this excess that enables and contests every performance, and which never fully appears within the performance itself. The psyche is not "in" the body, but in the very signifying process through which the body comes to appear; in the lapse in repetition as well as its compulsion, precisely what the performance seeks to deny, and that which compels it from the start. ("Imitation" 28)

Butler focuses on patterns of psychic repetition which disrupt unilinear narratives of gender acquisition through erotically charged identifications incurring unpredictability and slippage: "identification is never simply mimetic but involves a strategy of wish fulfillment...we take up identifications in order to facilitate or prohibit our own desires" ("Gender" 333).

Butler's critique of identity targets feminist attempts to stabilize and centralize gender identities and categories. While Butler has expressed her desire to negotiate between feminist work on gender and queer approaches to sexuality, she has tended to direct her deconstructive strategies at feminist thinkers in ways that homogenize and decontextualize maternal meanings. Disregarding vast differences between and within feminist texts, she asserts that:

For the most part, feminist critics concerned with the psychoanalytic problematic of identification have often focused on the question of a maternal identification and/or a maternal discourse evolved from the point of view of that identification and its difficulties...it tends to reinforce precisely the binary, heterosexist framework that carves up genders into masculine and feminine and forecloses an adequate description of the kinds of subversive and parodic convergences that characterize gay and lesbian culture. ("Proper" 66)

Attempting to disarticulate the question of "woman" from assumptions of primary and secondary maternal identifications, Butler addresses what 
she considers to be an essentialist legacy within feminist theory. In the process she overlooks many of the ambivalent and productive tensions within feminist psychoanalytic interpretations. Rejecting the maternal as a natural and universal foundation of a woman's psychic or political identity, Butler reduces feminist attempts to forefront maternal specificity to an identitarian tradition of gender conformity. By doing so, she bypasses feminist interest in tracing psycho-social-bodily vicissitudes of maternal subjectivity. While Butler's ostensible aim is to refuse totalizing maternal identities so as to allow for provisional readings of gender and sexuality, her reiteration of seamless maternal norms in abstraction from changing maternal relations mediated by inequalities of power, value and privilege end up reinforcing dominant conceptions of maternal difference.

Butler's unifying accounts of maternal-feminine identifications and desires not only miss an opportunity to read against the grain of heterosexual and oedipal inscriptions within feminist theory, but they provide little space to consider efforts to contextualize and pluralize maternal practices and knowledges. This leads Butler to bracket off historically and psychically diverse realities of mothering from monolithic epistemological readings of the Mother as a fixed reference point from which to undermine maternally grounded gender identities. Instead of grappling with contradictions and gaps of maternal identifications and desires, Butler solidifies the discursive effects of feminist discourse into a monolithic problem of gender essentialism. This reveals Butler's own paradoxical desire to control maternal meanings by delimiting their socio-historical proliferations, ensuring the relative stasis of the maternal body against which queer performativity is mobilized. Such oppositional ways of thinking discount mothers whose desires call into question heteronormative assumptions, overlooking the very possibility of psychic fluctuations and bodily instabilities that are seen as crucial for undermining homo/heterosexual certainties throughout Butler's writings. By challenging feminist appeals to maternal foundations solely in terms of the construction of unified gendered categories without paying attention to the psycho-social histories of mothers who interrupt normative categorical prescriptions at the level of their embodied interactions, Butler ends up foreclosing dialogical understandings of maternal subjectivities.

Similarly, Diana Fuss singles out regulative and normalizing maternal metaphors in her book Identification Papers against which she explores the textual and psychic volatility of identificatory desires. Fuss acknowledges "the astonishing capacity of identifications to reverse and disguise themselves, to multiply and contravene one another, to disappear and reappear 
years later renders identity profoundly unstable and perpetually open to radical change"(2). But while Fuss encourages an openness to the fluctuations of sexual identifications based on a deconstructive engagement with psychoanalytic theory, her engagement with Freud's maternal metaphors reveals some disturbing implications of reading for textual indeterminacy without simultaneously tracking historical relations of maternal subjects. The semiotic fluidity of subjectivity reaches its limit in Fuss' texts when she reacts to the regressive and irrational connotations of maternal identifications in psychoanalytic literature by turning away from maternal tropes which are seen as inextricably bound to pathologizing readings of homosexuality:

It cannot be a matter of indifference to feminist readers of Freud that "A Case of Homosexuality in a Woman" begins with the word "homosexuality" and concludes with the word "motherhood" - perhaps the most obvious staging of Freud's inability to think homosexuality outside the thematics of maternity. (Fuss 66)

Problematizing Freudian associations of motherhood and homosexual immaturity, Fuss calls for a dissociation between maternal and homosexual tropes. In other words, Freud's maternal representations are not interrogated in ways that would allow for alternative constellations of maternal and non-heterosexual desires, but rather indicate the need to separate them altogether. Fuss critically evaluates Freud's maternal metaphors from the perspective of autonomous and individuated homosexual desires unbounded by preoedipal maternal identifications. While Fuss challenges legacies within psychoanalysis to buttress heterosexuality as a developmental accomplishment away from maternal attachment, she unhinges homosexual-maternal connections without altering regressive accounts of maternal subjects. This unwittingly reinforces ahistorical assumptions about the maternal as a negative point of disinvestment for homo/heterosexual sexuality. Fuss' emphasis on the adverse effects of preoedipal fictions as inimical to independent and positive homosexual relations leads her to neglect the larger socio-cultural field of maternal devaluations. Fuss' psychoanalytic readings point in the direction of theorizing psycho-sexuality in terms of arbitrary signifiers rather than interactive social relations. Her work highlights figurative dimensions of maternal meanings, but she loses touch with social and discursive formations that would enable maternal subjects to differentially configure their own desires in relation to psychoanalytic narratives. Without repositioning the maternal as a complex subject of desire and identification beyond 
ahistorical notions of preoedipality, Fuss offers no way of criss-crossing maternal and sexual subjectivities alternatively.

In contrast to attempts by psychoanalytic feminists to elaborate intersubjective and semiotic readings of maternal subjectivity against the inertia of symbolic norms, Butler's and Fuss' readings abstract maternal subjects from relational practices by emphasizing the monolithic force of the Maternal as a closed representational system. While performatively playful reversals of codes and identities are hypothetically available to all within queer theory, historically gendered relations such as those of mothering become assimilated to their normative constructions. Queer theories have called attention to aspects of bodily and textual mobility of desire which challenge rationalist and identitarian models of subjectivity, but they have underplayed historical materialities and signifying relations which call for readings of sexuality mediated through various dimensions of subjective life. Queer theorists often reinforce oppositions between motherhood and sexuality which pervade dominant systems of knowledge and power at the same time that they attempt to deconstruct heteronormativity. I want to highlight contradictions between semiotically open, ethically responsive and pluralistic approaches within queer theory and their tendency to reinscribe motherhood as a docile mode of embodiment. While reproductive and familial discourses are forefronted in terms of their regulative features by queer theorists, the agency of mothers as acting, speaking and desiring subjects is rarely discussed. I am not suggesting queer readings of sexual desire be overtaken by social analysis of maternal relations, but that nuanced strategies for elaborating subversive sexualities be rethought to consider a much broader range of social subjectivities.

\section{Theorizing maternal "perversities"}

My desire to reorient feminist and queer psychoanalytic readings of the maternal away from normative bipolarities toward a greater attentiveness to (con)textually nuanced embodiments of maternal subjectivity is driven by what I consider to be some of the most intriguing aspects emerging out of these theoretical projects which point beyond reproductive maternal ideologies. Mobile notions of identification and desire launched by queer theorists are especially important for rethinking maternal subjectivity away from pregiven notions of gender identity which have tended to obscure all consideration of maternal non-conformity. At the same time, hesitations to engage with concrete relational differences of maternal subjects have diminished the cogency of queer anti-normative strategies. On 
the other hand feminist elaborations of relational intricacies of maternal subjectivity offer close-up perspectives on embodied practices overlooked by queer theorists, yet their reliance on gender as sexual difference as the over-riding context of maternal ethical relations avoids grappling with multiple desires which call into question the fixity of heterosexual family relations. It seems as if feminist explorations of maternal intersubjectivity and alterity are often at cross-purposes with queer disidentification with maternal genealogies altogether. Such a theoretical impasse raises interesting questions about the pervasiveness of binary constructions dividing subversive sexualities and ethical maternal norms.

Revealing specific positions of address and institutional locations, feminist and queer psychoanalytic theories are antagonistically marked by their ambivalence toward sexually "aberrant" maternal subjects. Rather than explain this ambivalence according to psychoanalytic oppositions (love/hate, prohibition/transgression, law/desire) configured intrapsychically in relation to the maternal, I am more interested in ways of thinking that combine psychic, social and semiotic analyses of maternal subjects. It seems important to follow multiple lines of investigation into the production of ambivalence not only in terms of individual struggles for love, knowledge and autonomy in relation to a primary maternal object or symbolic law, but also in terms of historical convergences of class, race and gender norms which incite and intensify oppositional responses to the maternal body. Problematizing ambivalence toward maternal sexualities in terms of social relations of othering which overlay psychic processes, shifts attention towards those fields of hierarchical and exclusionary powers which have avoided or denigrated "unruly" maternal subjects in accordance with prescriptive ideals. A common tendency running across feminist and queer psychoanalytic writings is to take for granted maternal figures constituted through dominant familial formations at the expense of considering subjugated and contested social histories of mothering. And whether responses are oriented toward an ethical affirmation of the relational contours of maternal subjectivity or a deconstruction of its gender identities, standards of critique continue to centre upon unified hegemonic power/knowledges of motherhood. It seems to me that what gets bypassed in the theoretical splitting between maternal intersubjectivity and subversive sexualities are precisely those socially disruptive elements of maternal practices which call into question divisions between ethical and sexual maternal relations. This suggests the importance of attending to socially specific relations which undermine normative binary divisions and reveal ambiguous figures of maternal power, desire and pleasure. 
I am going to end my essay by gesturing towards some interesting theoretical possibilities within Teresa de Lauretis' writings for redirecting a conversation beween feminist and queer thinkers. Rejecting hypostatizing narratives of sexual normality, de Lauretis combines Peirce's semiotic notion of experience, Foucault's notion of power and a psychoanalytic interest in "perverse" fantasy as a way of reading desiring subjectivity as an ongoing "practice of love." De Lauretis enables contextually nuanced understandings of sexual experience as an open-ended process of "habitchange" interlinking erotic interiority and social conditions of subjectivity:

It is these particular aspects of the concept of habit-change as I have elaborated it-the somatic, material, historical dimensions it inscribes in the subject- that are especially important to me in conceptualizing sexuality as a process of sexual structuring, a process overdetermined by both internal and external forces and constraints. (303)

De Lauretis' attention to concurrent dimensions of experience offers a framework for theorizing relational dynamics of maternal subjectivity including indeterminate "perverse" sexualities without anchoring desire to any single symbolic or imaginary figure. This makes it possible to theorize multiple sexualities experienced and reflexively articulated by mothers and daughters in the midst of constraining reproductive languages without diminishing tensions between various levels of feelings, perceptions, words and actions. De Lauretis hypothesizes that: "The seduction of the homosexual-maternal metaphor derives from the erotic charge of a desire for women which...affirms and enhances the female-sexed subject and represents her possibility of access to a sexuality autonomous from the male" (xvii), confounding pre-oedipal and oedipal maternal narratives which assume the need for relatively stable desires and identifications as a basis from which to evaluate "normal" trajectories of heterosexuality. Such affirmative rereadings of "perversion" challenge normalizing models of sexuality by attending to heterogeneous dimensions of bodily and fantasmatic desires which have no predetermined form or content, nor any single transgressive outcome. Who and what comes to signify desire becomes contingent upon the contexts and erotic predilections of the reading subject as part of an interactive process of semiosis. By posing questions of perversity and seduction as situated modes of address densely mediated through material conditions and social relations, de Lauretis avoids splitting motherhood and sexuality into oppositional features of subjectivity. This may be a point of departure for a queerly feminist maternal narrative? 
feminist sublimations, queer disidentifications $\cdot 37$

\section{Works Cited}

Benjamin, Jessica. The Bonds of Love: Psychoanalysis, Feminism and the Problem of Domination. New York: Pantheon Books, 1988.

-. Like Subjects, Love Objects: Essays on Recognition and Sexual Difference. New Haven: Yale UP, 1995.

Butler, Judith. "Against Proper Objects." Differences 6.2 (1994): 1-25.

-. Gender Trouble: Feminism and the Subversion of Identity. New York: Routledge, 1990.

- "Gender Trouble, Feminist Theory, and Psychoanalytic Discourse." Feminism/Postmodernism. Ed. Linda Nicholson. New York: Routledge, 1990. 324-340.

—. "Imitation and Gender Subordination." Inside/Out: Lesbian Theories, Gay Theories. Ed. Diana Fuss. New York: Routledge, 1991. 13-29. de Lauretis, Teresa. The Practice of Love: Lesbian Sexuality and Perverse Desire. Bloomington: Indiana UP, 1994.

Finzi, Silvia Vegetti. Mothering: Toward a New Psychoanalytic Construction. Trans. Katherine Jason. New York: Guilford Press, 1996.

Fuss, Diana. Identification Papers. New York: Routledge, 1995.

Kristeva, Julia. Tales of Love. Trans. Leon Roudiez. New York: Columbia UP, 1987.

-. "Women's Time." The Feminist Reader: Essays in Gender and the Politics of Literary Criticism. Eds. C. Belsey and J. Moore. New York: Basil Blackwell, 1989.

Martin, Biddy. "Sexualities without Genders and Other Queer Utopias." Diacritics (1994): 104- 121. 